\title{
PENGARUH LOKUS KENDALI, KAPABILITAS KEUANGAN, KESEDIAAN KEUANGAN DAN KECANGGIHAN KEUANGAN TERHADAP PERENCANAAN PENSIUN
}

\author{
Gatot Nazir Ahmad \\ Fakultas Ekonomi Universitas Negeri Jakarta \\ Email: ahmad72nazir@gmail.com \\ Mohammad Syafril Hamidi \\ Fakultas Ekonomi Universitas Negeri Jakarta \\ Email: hamidizy@gmail.com \\ Rida Prihatni \\ Fakultas Ekonomi Universitas Negeri Jakarta \\ Email: ridaprihatni@gmail.com
}

\begin{abstract}
ABSTRAK
Penelitian ini bertujuan menganalisis pengaruh lokus kendali (locus of control), kapabiltas keuangan (financial capability), kesediaan keuangan (financial willingness) dan kecanggihan keuangan (financial sophistication) terhadap perencanaan pensiun karyawan di DKI Jakarta. Variabel bebas yang digunakan pada penelitian ini adalah lokus kendali (locus of control), kapabiltas keuangan (financial capability), kesediaan keuangan (financial willingness) dan kecanggihan keuangan (financial sophistication). Variabel terikat yang digunakan adalah perencanaan pensiun. Ukuran sampel penelitian ini dihitung menggunakan rumus Krejcie-Morgan dan diperoleh jumlah sampel sebanyak 384 orang. Teknik analisis yang digunakan dalam penelitian ini adalah uji asumsi klasik, analisis deskriptif dan analisis regresi linier berganda. Teknik pengumpulan data menggunakan kuesioner yang telah diuji validitas dan reliabilitasnya. Hasil penelitian ini menunjukkan bahwa: (1) lokus kendali memiliki pengaruh yang signifikan terhadap perencanaan pensiun, (2) kapabilitas keuangan memiliki pengaruh yang signifikan terhadap perencanaan pensiun, (3) kesediaan keuangan memiliki pengaruh yang signifikan terhadap perencanaan pensiun, (4) kecanggihan keuangan memiliki pengaruh yang signifikan terhadap perencanaan pensiun.
\end{abstract}

Kata kunci: lokus kendali (locus of control), kapabiltas keuangan (financial capability), kesediaan keuangan (financial willingness), perencanaan pensiun (retirement planning) 


\section{Latar Belakang Masalah}

Kesejahteraan manusia sangat berkaitan erat dengan kemampuan finansial yang dimiliki. Kemampuan finansial bukan hanya pada kemampuan untuk mendapatkan pendapatan yang cukup melainkan juga kemampuan untuk mengelola keuangan secara bijaksana. Pengelolaan keuangan mempunyai peran yang sangat signifikan dalam menetukan tingkat kesejahteraan seseorang. Otoritas Jasa Keuangan telah melaksanakan Survei Nasional Literasi Keuangan pada tahun 2013 dan 2016. Berdasarkan survei tersebut indeks literasi keuangan masyarakat Indonesia mengalami peningkatan dari 21,8\% di tahun 2013 menjadi 29,7\% di tahun 2016, yang berarti dari setiap 100 penduduk hanya sekitar 30 orang yang termasuk kategori well literate. Dengan kondisi seperti ini, ditengarai masyarakat Indonesia belum sepenuhnya memiliki pengetahuan yang cukup mengenai bagaimana mengoptimalkan uang untuk kegiatan yang produktif. Di samping itu, masyarakat juga belum memahami dengan baik berbagai produk dan layanan jasa keuangan yang ditawarkan oleh lembaga jasa keuangan formal dan lebih tertarik pada tawaran-tawaran investasi lain yang berpotensi merugikan mereka (Otoritas Jasa Keuangan, 2017). Perbankan menjadi sektor yang memiliki indeks literasi keuangan tertinggi disusul pegadaian pada peringkat kedua dan sektor asuransi menduduki peringkat ketiga. Sedangkan dana pensiun yang bisa digunakan untuk memenuhi kebutuhan hidup setelah pensiun berada pada peringkat kelima. Pasar modal yang bisa digunakan menjadi sarana investasi untuk memenuhi kebutuhan jangka panjang berada pada peringkat keenam. Literasi keuangan sektoral ini sesuai dengan upaya mencapai tujuan keuangan yaitu menabung yang menduduki peringkat pertama. Peringkat kedua diduduki menyusun rencana keuangan dan posisi ketiga ditempati bekerja. Melakukan investasi untuk memenuhi kebutuhan jangka panjang berada pada posisi ketujuh. Upaya mencapai tujuan keuangan tersebut sesuai dengan tujuan keuangan yang ingin dicapai yaitu memenuhi kebutuhan pokok sehari-hari yang menjadi peringkat pertama. Mempertahankan hidup menempati peringkat kedua dan membayar pendidikan anak berada pada peringkat ketiga. Berdasarkan tujuan keuangan dan upaya mencapai tujuan keuangan serta indeks literasi keuangan sektoral dapat disimpulkan masyarakat Indonesia masih berfokus untuk memenuhi kebutuhan sehari-hari yang bersifat jangka pendek. Kebutuhan jangka panjang seperti menyiapkan dana pensiun atau hari tua belum menjadi prioritas utama. Terbukti dengan hanya 6,3\% yang menyatakan menyiapkan hari tua sebagai tujuan keuangannya. Kepemilikan rekening dana pensiun merupakan salah satu cara melakukan perencanaan pensiun. 
Perencanaan pensiun adalah proses menentukan tujuan pendapatan pensiun dan tindakan serta keputusan yang diperlukan untuk mencapai tujuan tersebut (Kagan, 2019).

Perilaku seseoarang untuk merencanakan pensiun bisa dipengaruhi oleh lokus kendali dan kapabilitas keuangan yang dimiliki. Lokus kendali adalah tingkatan individu percaya bahwa mereka mengendalikan masa depan mereka sendiri (Britt, Cumbie, \& Bell, 2013). Individu yang didorong secara internal percaya bahwa peristiwa di masa depan ditentukan oleh perilaku mereka sendiri (lokus kendali internal), sedangkan individu yang didorong dari luar percaya bahwa peristiwa di masa depan adalah hasil dari keberuntungan, kebetulan, nasib, atau karena kontrol orang lain (lokus kendali eksternal). Kempson et al., (2017) mengukur kapabilitas keuangan pada empat aspek, yaitu mengelola uang, merencanakan masa depan, memilih produk, dan tetap mendapatkan informasi.

Kesediaan keuangan dan kecanggihan keuangan juga dapat mempengaruhi perencanaan pensiun. Kesediaan keuangan (financial willingness) adalah tingkatan atau level dimana seseorang termotivasi untuk terlibat aktif dalam pengambilan keputusan keuangan (Philip, Heaton, Atkinson, \& Brierley, 2018). Kecanggihan finansial (financial sophistication) dapat digambarkan sebagai bentuk modal manusia yang meningkatkan kemampuan rumah tangga untuk membuat keputusan keuangan yang lebih efektif (Smith, Finke, \& Huston, 2012).

\section{Perumusan Masalah}

Bagaimana pengaruh lokus kendali, pengaruh kapabilitas keuangan, pengaruh kesediaan keuangan, dan pengaruh kecanggihan keuangan terhadap perencanaan pensiun karyawan di DKI Jakarta?

\section{Tujuan Penelitian}

Menganalisis pengaruh lokus kendali, pengaruh kapabilitas keuangan, pengaruh kesediaan keuangan, dan pengaruh kecanggihan keuangan terhadap perencanaan pensiun

\section{Manfaat Penelitian}

Penelitian ini dapat memberikan informasi mengenai pengaruh lokus kendali, pengaruh kapabilitas keuangan, pengaruh kesediaan keuangan, dan pengaruh kecanggihan keuangan terhadap perencanaan pensiun 


\section{TELAAH PUSTAKA}

Menurut Kagan (2019) perencanaan pensiun adalah proses menentukan tujuan pendapatan pensiun dan tindakan serta keputusan yang diperlukan untuk mencapai tujuan tersebut. Modigliani dan Brumberg (Kim dan Hanna, 2015) mengemukakan bahwa model standar untuk menganalisis perilaku tabungan pensiun adalah Model Life Cycle Saving (LCS). Model ini menyatakan bahwa konsumsi dan tabungan mencerminkan tahap individu dalam siklus hidup. Saat usia muda, konsumsi lebih tinggi dari penghasilan. Konsumsi yang lebih tinggi tersebut dibiayai dengan pinjaman. Saat usia paruh baya adalah masa akumulasi dimana seseorang menabung untuk masa pensiun dan membayar angsuran pinjamannya. Saat usia tua tabungan pensiun akan digunakan untuk membiayai konsumsi atau pengeluaran.

Menurut Britt et al. (2013) lokus kendali (locus of control) mempengaruhi perilaku keuangan sampai taraf tertentu. Sedangkan Perry dan Morris (2005) berpendapat bahwa kecenderungan konsumen untuk menabung, menganggarkan, dan mengendalikan pengeluaran sebagian bergantung pada tingkat kendali yang mereka rasakan atas hasil serta pengetahuan dan sumber daya keuangan.

Kapabilitas keuangan (financial capability) didefinisikan kemampuan dalam mengelola uang, merencanakan masa depan, memilih produk, dan tetap mendapatkan informasi (Kempson et al., 2017). Van Rooij, Lusardi, dan Alessie (2011) berpendapat bahwa adanya hubungan yang kuat dan positif antara pengetahuan keuangan dan perencanaan pensiun, mereka yang lebih berpengetahuan keuangan cenderung merencanakan pensiun.

Kesediaan keuangan (financial willingness) adalah tingkatan atau level dimana seseorang termotivasi untuk terlibat aktif dalam pengambilan keputusan keuangan (Philip et al., 2018). Kesediaan keuangan dapat dijelaskan menggunakan pendekatan teori kecenderungan untuk merencanakan (propensity to plan theory). Teori kecenderungan untuk merencanakan (propensity to plan theory) diartikan sebagai seperangkat sikap dan keterampilan yang mempengaruhi cara rumah tangga menangani tugas perencanaan keuangan (Lee dan Kim, 2016).

Kecanggihan finansial (financial sophistication) dapat digambarkan sebagai bentuk modal manusia yang meningkatkan kemampuan rumah tangga untuk membuat keputusan keuangan yang lebih efektif (Smith et al., 2012). Kecanggihan keuangan berpengaruh terhadap kesiapan pensiun yang memadai (Kim dan Hanna, 2015) 


\section{MODEL PENELITIAN}

Berdasarkan uraian seluruh variabel dalam penelitian ini, maka dapat dibuat kerangka model penelitian berikut ini:

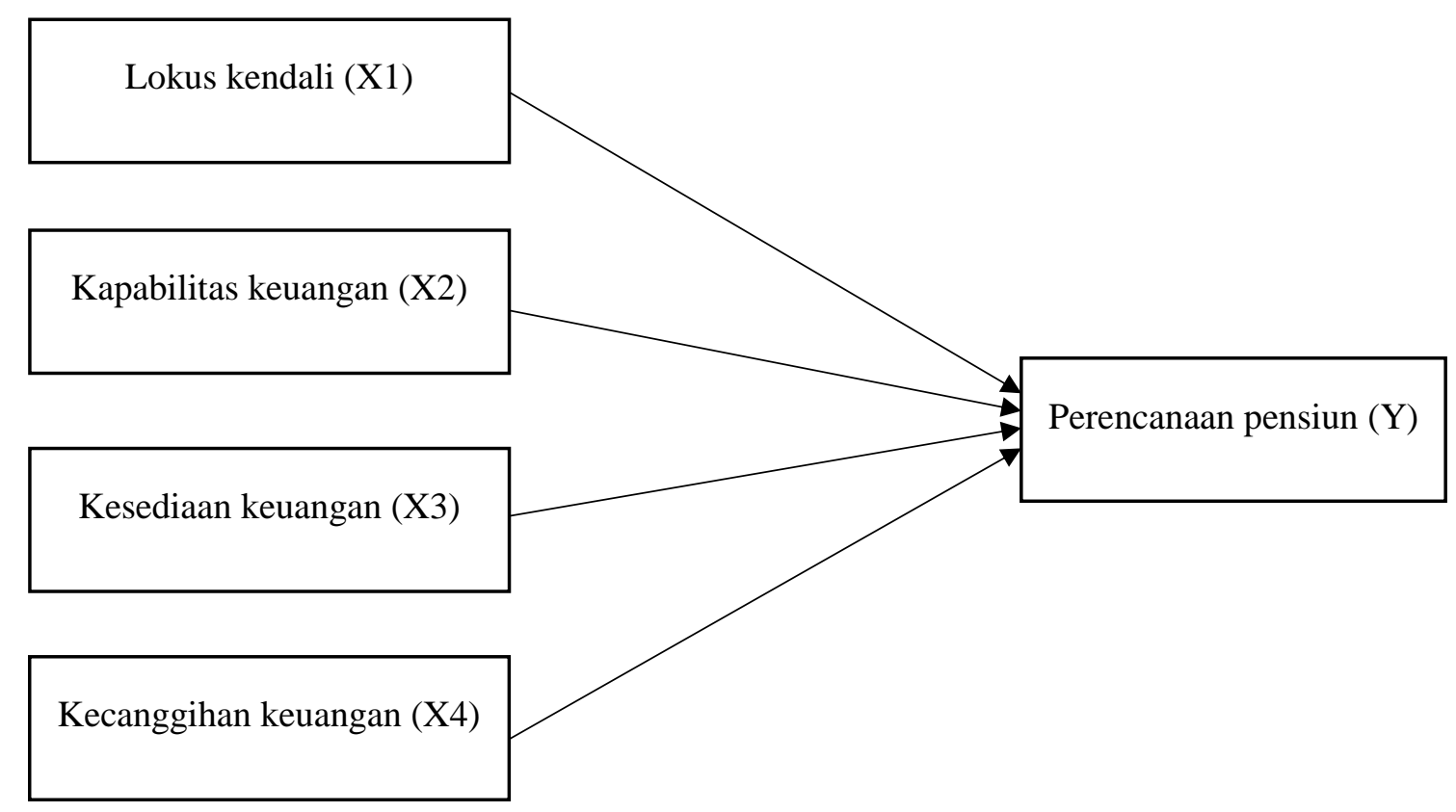

Gambar 1. Kerangka Penelitian

Sumber: Data diolah peneliti (2020)

\section{Perumusan Hipotesis Penelitian}

Berdasarkan teori dan kerangka berpikir yang sudah diuraikan sebelumnya, hipotesis disusun sebagai berikut:

1. H1 : Lokus kendali mempengaruhi perencanaan pensiun karyawan di DKI Jakarta

2. H2 : Kapabilitas keuangan mempengaruhi perencanaan pensiun karyawan di DKI Jakarta

3. H3 : Kesediaan keuangan mempengaruhi perencanaan pensiun karyawan di DKI Jakarta

4. H4 : Kecanggihan keuangan mempengaruhi perencanaan pensiun karyawan di DKI Jakarta 


\section{METODE PENELITIAN}

\section{Objek dan Ruang Lingkup Penelitian}

Objek penelitian ini adalah lokus kendali, kapabilitas keuangan, kesediaan keuangan, kecanggihan keuangan dan perencanaan pensiun. Data yang digunakan dalam penelitian ini adalah data primer yang diperoleh dari kuisioner yang diisi oleh responden karyawan di DKI Jakarta.

\section{Metode Penelitian}

Metode penelitian yang digunakan dalam penelitian ini adalah metode survey. Analisis statistik deskriptif dipakai untuk memperoleh data yang digunakan untuk menjelaskan kondisi variabel penelitian, sedangkan untuk mengetahui pengaruh variabel bebas terhadap variabel terikat menggunakan analisis statistik parametrik.

\section{Metode Penentuan Populasi dan Sampel}

\section{Populasi}

Populasi dalam penelitian ini adalah penduduk DKI Jakarta yang memiliki status pekerjaan utama sebagai karyawan per Agustus 2019 adalah 3.127.591 orang (Badan Pusat Statistik Provinsi DKI Jakarta, 2019).

\section{Sampel}

Jumlah sampel dihitung dengan menggunakan rumus Krejcie-Morgan (Sanusi, 2012). Jumlah sampel yang diperlukan dalam penelitian ini adalah 384 orang.

\section{HASIL PENELITIAN DAN PEMBAHASAN}

\section{Karakteristik Responden}

\section{Jenis Kelamin}

Tabel 1 Responden Berdasarkan Jenis Kelamin

\begin{tabular}{llrrrr}
\hline & & & & \multicolumn{2}{c}{ Cumulative } \\
& & Frequency & Percent & Valid Percent & \multicolumn{1}{c}{ Percent } \\
\hline \multirow{2}{*}{ Valid } & Laki-laki & 179 & 46,6 & 46,6 & 46,6 \\
& Perempuan & 205 & 53,4 & 53,4 & 100,0 \\
& Total & 384 & 100,0 & 100,0 & \\
\cline { 2 - 5 }
\end{tabular}


http://doi.org/10.21009/JRMSI

Sumber : Data primer diolah peneliti (2020)

Berdasarkan Tabel 1 di atas diketahui bahwa sebanyak 179 responden (46,6\%) dalam penelitian ini berjenis kelamin laki-laki, sedangkan sisanya sebanyak 205 responden $(53,4 \%)$ berjenis kelamin perempuan.

Usia

Tabel 2 Responden Berdasarkan Usia

\begin{tabular}{cccccc}
\hline & Usia & Frequency & Percent & Valid Percent & $\begin{array}{c}\text { Cumulative } \\
\text { Percent }\end{array}$ \\
\hline \multirow{6}{*}{ Valid } & $18-24$ tahun & 18 & 4,7 & 4,7 & 4,7 \\
& $25-34$ tahun & 180 & 46,9 & 46,9 & 51,6 \\
& $35-44$ tahun & 130 & 33,9 & 33,9 & 85,4 \\
& $45-54$ tahun & 47 & 12,2 & 12,2 & 97,7 \\
& $55-64$ tahun & 9 & 2,3 & 2,3 & 100,0 \\
\cline { 2 - 5 } & Total & 384 & 100,0 & 100,0 & \\
\hline
\end{tabular}

Sumber : Data primer diolah peneliti (2020)

Berdasarkan Tabel 2 di atas dapat terlihat bahwa sebanyak 18 responden $(4,7 \%)$ berada pada kelompok usia 18-24 Tahun, sebanyak 180 responden (46,9\%) berada pada kelompok usia 25-34 Tahun, sebanyak 130 responden (33,9\%) berada pada kelompok usia 35-44 Tahun, sebanyak 47 responden (12,2\%) berada pada kelompok usia 45-54 Tahun, dan sisanya sebanyak 9 responden $(2,3 \%)$ berada pada kelompok usia 55-64 Tahun.

\section{Status Pernikahan}

Tabel 3 Responden Berdasarkan Status Pernikahan

\begin{tabular}{llcccc}
\hline & Frequency & Percent & Valid Percent & $\begin{array}{c}\text { Cumulative } \\
\text { Percent }\end{array}$ \\
\hline & Lajang, tinggal dengan orang tua & 54 & 14,1 & 14,1 & 14,1 \\
& $\begin{array}{l}\text { Lajang, tinggal sendiri } \\
\text { Menikah, dengan anak tinggal di }\end{array}$ & 69 & 18,0 & 18,0 & 32,0 \\
& $\begin{array}{l}\text { rumah } \\
\text { Valid }\end{array}$ & 212 & 55,2 & 55,2 & 87,2 \\
& Menikah, tidak ada anak & 42 & 10,9 & 10,9 & 98,2 \\
& $\begin{array}{l}\text { Orang tua tunggal dengan anak- } \\
\text { anak di rumah }\end{array}$ & 2 & 0,5 & 0,5 & 98,7 \\
& $\begin{array}{l}\text { Lainnya } \\
\text { Total }\end{array}$ & 5 & 1,3 & 1,3 & 100,0 \\
Sumber : & Data primer diolah peneliti (2020) & 384 & 100,0 & 100,0 &
\end{tabular}


Berdasarkan Tabel 3 di atas dapat terlihat bahwa sebanyak 54 responden $(14,1 \%)$ berstatus lajang tinggal dengan orang tua, dan sebanyak 69 responden (18\%) berstatus lajang tinggal sendiri, sebanyak 212 responden $(55,2 \%)$ berstatus menikah, dengan anak tinggal di rumah, sebanyak 42 responden $(10,9 \%)$ berstatus menikah tidak ada anak, sebanyak 2 responden $(0,5 \%)$ berstatus orang tua tunggal dengan anak-anak di rumah, sedangkan sisanya sebanyak 5 responden $(1,3 \%)$ berstatus lainnya.

\section{Penghasilan Tahunan}

Tabel 4 Responden Berdasarkan Penghasilan Tahunan

\begin{tabular}{|c|c|c|c|c|c|}
\hline & Penghasilan Tahunan & Frequency & Percent & Valid Percent & $\begin{array}{c}\text { Cumulative } \\
\text { Percent }\end{array}$ \\
\hline \multirow{5}{*}{ Valid } & $250.000 .000-500.000 .000$ & 88 & 22,9 & 22,9 & 22,9 \\
\hline & $50.000 .000-250.000 .000$ & 185 & 48,2 & 48,2 & 71,1 \\
\hline & Kurang dari 50.000 .000 & 67 & 17,4 & 17,4 & 88,5 \\
\hline & Lebih dari 500.000 .000 & 44 & 11,5 & 11,5 & 100,0 \\
\hline & Total & 384 & 100,0 & 100,0 & \\
\hline
\end{tabular}

Berdasarkan Tabel 4 di atas dapat terlihat bahwa sebanyak 88 responden $(22,9 \%)$ memiliki penghasilan tahunan sebanyak 250.000.000 - 500.000.000, sebanyak 185 responden $(48,2 \%)$ memiliki penghasilan tahunan sebanyak 50.000.000 - 250.000.000, sebanyak 67 responden $(17,4 \%)$ memiliki penghasilan tahunan sebanyak kurang dari 50.000.000, sedangkan sisanya sebanyak 44 responden $(11,5 \%)$ memiliki penghasilan tahunan sebanyak lebih dari 500.000.000. 


\section{Domisili}

Tabel 5 Responden Berdasarkan Domisili

\begin{tabular}{cccccc}
\hline Domisili & Frequency & Percent & Valid Percent & $\begin{array}{c}\text { Cumulative } \\
\text { Percent }\end{array}$ \\
\hline \multirow{2}{*}{ Valid } & Jakarta Barat & 46 & 12,0 & 12,0 & 12,0 \\
& Jakarta Pusat & 50 & 13,0 & 13,0 & 25,0 \\
& Jakarta Selatan & 140 & 36,5 & 36,5 & 61,5 \\
& Jakarta Timur & 124 & 32,3 & 32,3 & 93,8 \\
& Jakarta Utara & 24 & 6,3 & 6,3 & 100,0 \\
\hline
\end{tabular}

Sumber : Data primer diolah peneliti (2020)

Berdasarkan Tabel 5 di atas dapat terlihat bahwa sebanyak 46 responden (12\%) berdomisili di Jakarta Barat, sebanyak 50 responden (13\%) berdomisili di Jakarta Pusat, sebanyak 140 responden (36,5\%) berdomisili di Jakarta Selatan, sebanyak 124 responden $(32,3 \%)$ berdomisili di Jakarta Timur, dan sisanya sebanyak 24 responden $(6,3 \%)$ berdomisili di Jakarta Utara.

\section{Status Pekerjaan}

Tabel 6 Responden Berdasarkan Status Pekerjaan

\begin{tabular}{|c|c|c|c|c|c|}
\hline & Status Pekerjaan & Frequency & Percent & $\begin{array}{c}\text { Valid } \\
\text { Percent }\end{array}$ & $\begin{array}{c}\text { Cumulative } \\
\text { Percent }\end{array}$ \\
\hline \multirow{5}{*}{ Valid } & Bekerja paruh waktu & 19 & 4,9 & 4,9 & 4,9 \\
\hline & Bekerja penuh waktu & 342 & 89,1 & 89,1 & 94,0 \\
\hline & Bekerja penuh waktu sambil sekolah & 21 & 5,5 & 5,5 & 99,5 \\
\hline & Pengangguran & 2 &, 5 &, 5 & 100,0 \\
\hline & Total & 384 & 100,0 & 100,0 & \\
\hline
\end{tabular}

Sumber : Data primer diolah peneliti (2020)

Berdasarkan Tabel 6 di atas dapat terlihat bahwa sebanyak 19 responden $(4,9 \%)$ memiliki status bekerja paruh waktu, sebanyak 342 responden $(89,1 \%)$ memiliki status bekerja penuh waktu, sebanyak 21 responden $(5,5 \%)$ memiliki status bekerja penuh waktu sambil sekolah, dan sisanya sebanyak 2 responden (5\%) memiliki status pengangguran. 


\section{Tingkat Pendidikan}

Tabel 7 Responden Berdasarkan Pendidikan

\begin{tabular}{lccccc}
\hline & Pendidikan & Frequency & Percent & Valid Percent & $\begin{array}{c}\text { Cumulative } \\
\text { Percent }\end{array}$ \\
\hline \multirow{3}{*}{ Valid } & Di atas Strata 1 & 136 & 35,4 & 35,4 & 35,4 \\
& Diploma 3 atau Strata 1 & 241 & 62,8 & 62,8 & 98,2 \\
& SMA & 7 & 1,8 & 1,8 & 100,0 \\
\hline Sumber $:$ Data primer diolah peneliti $(2020)$ & 384 & 100,0 & 100,0 &
\end{tabular}

Berdasarkan Tabel 7 di atas dapat terlihat bahwa sebanyak 136 responden $(35,4 \%)$ memiliki status pendidikan Diatas Strata 1, sebanyak 241 responden $(62,8 \%)$ memiliki status pendidikan Diploma 3 atau Strata 1, dan sisanya sebanyak 7 responden $(1,8 \%)$ memiliki status pendidikan SMA.

\section{Kepemilikan Rumah}

Tabel 8 Responden Berdasarkan Kepemilikan Rumah

\begin{tabular}{|c|c|c|c|c|c|}
\hline & Kepemilikan Rumah & Frequency & Percent & $\begin{array}{c}\text { Valid } \\
\text { Percent }\end{array}$ & $\begin{array}{c}\text { Cumulative } \\
\text { Percent }\end{array}$ \\
\hline \multirow{7}{*}{ Valid } & Tidak, saya menyewa & 59 & 15,4 & 15,4 & 22,4 \\
\hline & $\begin{array}{l}\text { Tidak, seseorang yang tinggal dengan } \\
\text { saya memiliki atau menyewa properti } \\
\text { tempat saya tinggal }\end{array}$ & 30 & 7,8 & 7,8 & 30,2 \\
\hline & $\begin{array}{l}\text { Ya, saya memiliki properti investasi } \\
\text { tetapi tinggal di tempat lain }\end{array}$ & 36 & 9,4 & 9,4 & 39,6 \\
\hline & $\begin{array}{c}\text { Ya, saya memiliki rumah tempat saya } \\
\text { tinggal }\end{array}$ & 142 & 37,0 & 37,0 & 76,6 \\
\hline & $\begin{array}{c}\text { Ya, saya memiliki rumah tempat saya } \\
\text { tinggal dengan KPR }\end{array}$ & 90 & 23,4 & 23,4 & 100,0 \\
\hline & Lainnya & 27 & 7,0 & 7,0 & 7,0 \\
\hline & Total & 384 & 100,0 & 100,0 & \\
\hline
\end{tabular}

Sumber : Data primer diolah peneliti (2020)

Berdasarkan Tabel 8 di atas dapat terlihat bahwa sebanyak 59 responden $(15,4 \%)$ menyewa rumah, sebanyak 30 responden (7,8\%) menumpang tinggal, sebanyak 36 responden $(9,4 \%)$ memiliki property investasi tetapi tinggal di tempat lain, sebanyak 142 responden (37\%) memiliki rumah, sebanyak 90 responden $(23,4 \%)$ memiliki rumah dengan KPR, dan sisanya sebanyak 27 responden (7\%) menjawab dengan lainnya. 


\section{Hasil Pengujian Data}

\section{Uji Validitas}

Uji validitas dilakukan dengan bantuan software SPSS 25. Pengujian ini dilakukan dengan cara membandingkan nilai $r$ hitung (pearson corellation) dengan $r$ tabel. Item dinyatakan valid dan dapat digunakan untuk penelitian jika $r$ hitung lebih besar dari $r$ tabel dan bernilai positif (Ghozali, 2016). Pengambilan keputusan dilakukan pada taraf degree of freedom (df) $=n-2$, dimana $n=384$, sehingga $\mathrm{df}=384-2=382$ dengan siginifikansi 5\% (tingkat kepercayaan 95\% atau $\alpha=0,05)$, sehingga nilai $r$ tabel diketahui sebesar 0,100 . Hasil uji validitas data dapat dilihat pada tabel di bawah.

Tabel 9 Hasil Uji Validitas

\begin{tabular}{|c|c|c|c|c|}
\hline Variabel & Item & r-hitung & r-tabel & Hasil \\
\hline \multirow{5}{*}{$\begin{array}{l}\text { Perencanaan } \\
\text { Pensiun }\end{array}$} & PEN1 & $0,845 * *$ & 0,100 & Valid \\
\hline & PEN2 & $0,802 * *$ & 0,100 & Valid \\
\hline & PEN3 & $0,804 * *$ & 0,100 & Valid \\
\hline & PEN4 & $0,690 * *$ & 0,100 & Valid \\
\hline & PEN5 & $0,761 * *$ & 0,100 & Valid \\
\hline \multirow{14}{*}{ Lokus Kendali } & LOC1.1 & $0,493 * *$ & 0,100 & Valid \\
\hline & LOC 1.2 & $0,714 * *$ & 0,100 & Valid \\
\hline & LOC 1.3 & $0,764 * *$ & 0,100 & Valid \\
\hline & $\mathrm{LOC} 1.4$ & $0,622 * *$ & 0,100 & Valid \\
\hline & LOC2.1 & $0,777 * *$ & 0,100 & Valid \\
\hline & LOC2.2 & $0,683 * *$ & 0,100 & Valid \\
\hline & LOC2.3 & $0,784 * *$ & 0,100 & Valid \\
\hline & $\mathrm{LOC} 2.4$ & $0,721 * *$ & 0,100 & Valid \\
\hline & LOC2.5 & $0,837 * *$ & 0,100 & Valid \\
\hline & LOC 3.1 & $0,770 * *$ & 0,100 & Valid \\
\hline & LOC3.2 & $0,729 * *$ & 0,100 & Valid \\
\hline & LOC 3.3 & $0,708 * *$ & 0,100 & Valid \\
\hline & LOC 3.4 & $0,686^{* *}$ & 0,100 & Valid \\
\hline & LOC3.5 & $0,814 * *$ & 0,100 & Valid \\
\hline \multirow{4}{*}{$\begin{array}{c}\text { Kapabilitas } \\
\text { Keuangan }\end{array}$} & FC1 & $0,884 * *$ & 0,100 & Valid \\
\hline & $\mathrm{FC} 2$ & $0,889 * *$ & 0,100 & Valid \\
\hline & FC3 & $0,827 * *$ & 0,100 & Valid \\
\hline & FW1 & $0,577 * *$ & 0,100 & Valid \\
\hline \multirow{5}{*}{$\begin{array}{l}\text { Kesediaan } \\
\text { Keuangan }\end{array}$} & FW2.1 & $0,556 * *$ & 0,100 & Valid \\
\hline & FW2.2 & $0,746^{* *}$ & 0,100 & Valid \\
\hline & FW2.3 & $0,810^{* *}$ & 0,100 & Valid \\
\hline & FW2.4 & $0,770 * *$ & 0,100 & Valid \\
\hline & FW3 & $0,769 * *$ & 0,100 & Valid \\
\hline
\end{tabular}




\begin{tabular}{ccccc} 
& FW4.1 & $0,689^{* *}$ & 0,100 & Valid \\
& FW4.2 & $0,711^{* *}$ & 0,100 & Valid \\
& FW4.3 & $0,664^{* *}$ & 0,100 & Valid \\
Kecanggihan & FS1 & $0,709^{* *}$ & 0,100 & Valid \\
Keuangan & FS2 & $0,796^{* *}$ & 0,100 & Valid \\
& FS3 & $0,819^{* *}$ & 0,100 & Valid \\
& FS4 & $0,737^{* *}$ & 0,100 & Valid \\
\hline
\end{tabular}

Sumber: Output SPSS 25 diolah peneliti (2020)

Berdasarkan hasil output SPSS pada tabel di atas, terlihat bahwa pada masig-masing indikator terdapat tanda ** pada kolom $\mathrm{r}$ hitung, yang menunjukkan bahwa indikator tersebut telah valid pada level signifikansi 0.05 (uji dua arah). Diketahui pula bahwa seluruh item telah memiliki nilai $r$ hitung (pearson correlation) di atas nilai $r$ table ( $r$ hitung $>0,100$ ), sehingga dapat disimpulkan bahwa item-item yang digunakan dalam penelitian ini telah memenuhi syarat validitas.

\section{Uji Reliabilitas}

Uji reliabilitas dilakukan secara one shot atau pengukuran satu kali saja melalui pengukuran Cronbach Alpha. Suatu variabel dikatakan memiliki tingkat reliabel tinggi jika nilai koefisien Crobach Alpha $(\alpha)>0,70$ (Ghozali, 2016). Hasil uji reliabilitas penelitian ini tersaji pada tabel di bawah.

Tabel 10 Hasil Uji Reliabilitas

\begin{tabular}{lccc}
\hline \multicolumn{1}{c}{ Variabel } & Cronbach's Alpha & Cut off value & Hasil \\
\hline Perencanaan Pensiun & 0,834 & 0,70 & Reliabel \\
Lokus Kendali & 0,928 & 0,70 & Reliabel \\
Kapabilitas Keuangan & 0,835 & 0,70 & Reliabel \\
Kesediaan Keuangan & 0,870 & 0,70 & Reliabel \\
Kecanggihan Keuangan & 0,765 & 0,70 & Reliabel \\
\hline
\end{tabular}

Sumber: Output SPSS 25 diolah peneliti (2020)

Tabel di atas memperlihatkan bahwa seluruh variabel yang digunakan dalam penelitian ini dinyatakan reliabel karena setiap variabel yang diteliti telah memiliki nilai Crobach Alpha $(\alpha)$ lebih besar dari 0,7 .

\section{Uji Asumsi Klasik}

\section{Uji Normalitas}


Uji normalitas bertujuan untuk menguji apakah dalam sebuah model regresi, variabel pengganggu atau residual terdistribusi secara normal (Ghozali, 2016). Pengujian ini dapat dilakukan dengan menganalisa grafik Histogram dan pola normal P-Plot, serta melalui pengujian one sampel Kolmogorov-Smirnov. Adapun hasil uji normalitas dalam penelitian ini sebagai berikut:

Tabel 11 Hasil Uji Normalitas One Sample Kolmogorov-Smirnov

\begin{tabular}{llr}
\hline \multicolumn{2}{c}{ One-Sample Kolmogorov-Smirnov Test } \\
\hline N & & $\begin{array}{c}\text { Unstandardized } \\
\text { Residual }\end{array}$ \\
Normal Parameters & & 384 \\
& Mean & 0,0000000 \\
Most Extreme Differences & Std. Deviation & 2,56182295 \\
& Absolute & 0,042 \\
& Positive & 0,042 \\
Test Statistic & Negative & $-0,027$ \\
Asymp. Sig. (2-tailed) & & 0,042 \\
\hline
\end{tabular}

a. Test distribution is Normal.

b. Calculated from data.

c. Lilliefors Significance Correction.

Sumber: Output SPSS 25 diolah peneliti (2020)

Hasil uji one sample Kolmogorov-Smirnov pada tabel di atas menunjukkan nilai signifikansi sebesar 0,099>0,05, sehingga dapat disimpulkan bahwa data dalam penelitian ini memenuhi syarat uji normalitas.

\section{Uji Multikolinearitas}

Uji multikolinearitas bertujuan untuk menguji apakah model regresi ditemukan adanya korelasi antar variabel bebas (independen). Uji multikolinearitas dapat dilihat melalui nilai tolerance dan Variance Inflation Factor (VIF). Nilai cut-off yang umum dipakai untuk menunjukkan adanya multikolinearitas adalah nilai Tolerance $\leq 0.10$ atau nilai VIF $\geq 10$. Hasil uji multikolinearitas disajikan dalam penelitian ini tersaji pada tabel di bawah. 
Tabel 12 Hasil Uji Multikolinearitas

\begin{tabular}{llcc}
\hline \multicolumn{4}{c}{ Coefficients $^{\mathbf{a}}$} \\
\hline \multirow{3}{*}{ Model } & & Collinearity Statistics \\
1 & Locus of Control & 0,639 & 1,564 \\
& Financial Capability & 0,678 & 1,476 \\
& Financial Willingness & 0,550 & 1,819 \\
& Financial Sophisticated & 0,563 & 1,775 \\
\hline
\end{tabular}

a. Dependent Variable: Pension Plan

Sumber: Output SPSS 25 diolah peneliti (2020)

Berdasarkan tabel di atas dapat diketahui bahwa nilai VIF untuk semua variabel tidak lebih dari 10 dan nilai tolerance semua variabel juga di atas 0,10, sehingga dapat disimpulkan bahwa semua variabel independen dalam penelitian ini tidak mengalami gejala multikolinearitas.

\section{Uji Heteroskedastisitas}

Menurut (Ghozali, 2016) uji heteroskedastisitas bertujuan untuk menguji apakah dalam model regresi terjadi ketidaksamaan variance residual satu pengamatan ke pengamatan lain. Untuk model regresi ideal yaitu yang tidak terjadi heteroskedastisitas. Cara mendeteksi ada tidaknya heteroskedastisitas dapat dilakukan melalui Uji Gletser (Ghozali, 2016). Uji gletser mengusulkan untuk meregresi nilai absolut residual (dalam penelitian ini diberi kode ABSRESID) terhadap variabel independen. Dikatakan tidak terjadi heteroskedastisitas jika nilai signifikansi variabel independen lebih dari 0,05. Hasil uji heteroskedastisitas dapat dilihat pada tabel di bawah.

Tabel 13 Hasil Uji Heterokedastisitas (Uji Gletser)

\begin{tabular}{|c|c|c|c|c|c|c|}
\hline \multicolumn{7}{|c|}{ Coefficients $^{\mathrm{a}}$} \\
\hline & & \multirow{2}{*}{\multicolumn{2}{|c|}{$\begin{array}{c}\text { Unstandardized } \\
\text { Coefficients }\end{array}$}} & \multirow{2}{*}{\multicolumn{3}{|c|}{$\begin{array}{l}\text { Standardized } \\
\text { Coefficients }\end{array}$}} \\
\hline & & & & & & \\
\hline \multicolumn{2}{|c|}{ Model } & $\mathrm{B}$ & Std. Error & Beta & $\mathrm{t}$ & Sig. \\
\hline \multirow[t]{5}{*}{1} & (Constant) & 2,238 & 0,509 & & 04,396 & 0,000 \\
\hline & Locus of Control & 0,006 & 0,011 & 0,034 & 0,528 & 0,598 \\
\hline & Financial Capability & 0,004 & 0,038 & 0,007 & 0,116 & 0,908 \\
\hline & Financial Willingness & $-0,020$ & 0,017 & $-0,081$ & $-1,172$ & 0,242 \\
\hline & Financial Sophisticated & 0,000 & 0,034 & 0,001 & 0,011 & 0,991 \\
\hline
\end{tabular}

a. Dependent Variable: ABSRESID

Sumber: Output SPSS 25 diolah peneliti (2020) 
Berdasar hasil uji Gletser pada tabel di atas, dapat terlihat bahwa nilai signifikansi untuk seluruh variabel independen lokus kendali, Kapabilitas Keuangan, Kesediaan Keuangan dan Kecanggihan Keuangan secara berturut-turut adalah 0.598, 0.908, 0.242, 0.991 yang seluruhnya memiliki nilai signifikansi lebih besar dari 0,05 .

\section{Pengujian Hipotesis}

Tabel 14 Hasil Uji Hipotesis (Uji-t)

\begin{tabular}{lcccc}
\hline \multicolumn{1}{c}{ Variable } & Coefficients (B) & t & Sig. & Hasil \\
\hline (Constant) & 3,582 & 4,223 & 0,000 & \\
Locus of Control & 0,093 & 4,966 & 0,000 & Signifikan \\
Financial Capability & 0,188 & 2,984 & 0,003 & Signifikan \\
Financial Willingness & 0,145 & 5,006 & 0,000 & Signifikan \\
Financial Sophisticated & 0,226 & 3,963 & 0,000 & Signifikan \\
\hline
\end{tabular}

Sumber: Output SPSS 25 diolah peneliti (2020)

Berdasarkan pengujian hipotesis melalui uji-t pada tabel di atas, maka terlihat bahwa keempat variabel independen dalam penelitian ini memiliki hasil signifikan yang dapat dijabarkan sebagai berikut: 1). Hasil uji t pada variabel lokus kendali (locus of control) menunjukkan nilai t-statistik $(4,966)>\mathrm{t}$-tabel $(1,960)$ dan nilai signifikansi $0.000<0.05$, yang menunjukkan bahwa terdapat pengaruh signifikan lokus kendali terhadap perencanaan pensiun. Dengan demikian Hipotesis H1 diterima. 2). Hasil uji t pada variabel kapabilitas keuangan (financial capability) menunjukkan nilai t-statistik $(2,984)>$ t-tabel $(1,960)$ dan nilai signifikansi $0.003<0.05$, yang menunjukkan bahwa terdapat pengaruh signifikan kapabilitas keuangan terhadap perencanaan pensiun. Dengan demikian Hipotesis H2 diterima. 3). Hasil uji t pada variabel kesediaan keuangan (financial willingness) menunjukkan nilai t-statistik $(5,006)>$ t-tabel $(1,960)$ dan nilai signifikansi $0.000<0.05$, yang menunjukkan bahwa terdapat pengaruh signifikan kesediaan keuangan terhadap perencanaan pensiun. Dengan demikian Hipotesis H3 diterima. 4). Hasil uji t pada variabel kecanggihan keuangan (financial sophisticated) menunjukkan nilai t-statistik $(3,963)>$ t-tabel $(1,960)$ dan nilai signifikansi $0.000<0.05$, yang menunjukkan bahwa terdapat pengaruh signifikan kecanggihan keuangan terhadap perencanaan pensiun. Dengan demikian Hipotesis H4 diterima. 


\section{KESIMPULAN DAN SARAN}

\section{Kesimpulan}

Berdasarkan hasil penelitian dan pembahasan, maka dapat ditarik kesimpulan sebagai berikut: 1). Terdapat pengaruh lokus kendali terhadap perencanaan pensiun. Hal ini dapat dibuktikan dari hasil analisis regresi yang menunjukkan tingkat signifikan sebesar 0.000 yang berada di bawah batas maksimum toleransi kesalahan yaitu 0,05. Dengan demikian H1 didukung oleh data dan hasil ini mendukung hipotesis awal peneliti yang diajukan dalam penelitian. 2). Terdapat pengaruh kapabilitas keuangan terhadap perencanaan pensiun. Hal ini dapat dibuktikan dari hasil analisis regresi yang menunjukkan tingkat signifikan sebesar 0.003 yang berada di bawah batas maksimum toleransi kesalahan yaitu 0,05. Dengan demikian H2 didukung oleh data dan hasil ini mendukung hipotesis awal peneliti yang diajukan dalam penelitian. 3). Terdapat pengaruh kesediaan keuangan terhadap perencanaan pensiun. Hal ini dapat dibuktikan dari hasil analisis regresi yang menunjukkan tingkat signifikan sebesar 0.000 yang berada di bawah batas maksimum toleransi kesalahan yaitu 0,05. Dengan demikian H3 didukung oleh data dan hasil ini mendukung hipotesis awal peneliti yang diajukan dalam penelitian. 4). Terdapat pengaruh kecanggihan keuangan terhadap perencanaan pensiun. Hal ini dapat dibuktikan dari hasil analisis regresi yang menunjukkan tingkat signifikan sebesar 0.000 yang berada di bawah batas maksimum toleransi kesalahan yaitu 0,05. Dengan demikian H4 didukung oleh data dan hasil ini mendukung hipotesis awal peneliti yang diajukan dalam penelitian.

\section{Saran}

Berdasarkan hasil penelitian dan pembahasan, maka dapat diberikan saran sebagai berikut: 1). Agar menambah jumlah sampel untuk meningkatkan akurasi hasil penelitian selanjutnya. 2). Memilih populasi yang berbeda untuk menambah hasil penelitian berikutnya. 3). Bisa menggunakan indikator dan atau variabel lain yang dapat mempengaruhi perencanaan pensiun. 4). Bisa memakai metode analisis yang lain untuk penelitian selanjutnya. 


\section{DAFTAR PUSTAKA}

Badan Pusat Statistik Provinsi DKI Jakarta. (2019). Indikator Kesejahteraan Rakyat Provinsi DKI Jakarta 2019. Jakarta.

Britt, S., Cumbie, J., \& Bell, M. (2013). The Influence of Locus of Control. College Student Journal, 47(1), 178-185.

Ghozali, I. (2016). Aplikasi Analisis Multivariate Dengan Program IBM SPSS 23 (VIII). Semarang: BPFE Universitas Diponegoro.

Kagan, J. (n.d.). No Title. Retrieved December 25, 2019, from https://www.investopedia.com/terms/r/retirement-planning.asp

Kempson, E., Finney, A., \& Poppe, C. (2017). Financial Well-Being A Conceptual Model and Preliminary Analysis. In Consumption Research Norway.

Kim, K. T., \& Hanna, S. (2015). Does Financial Sophistication Matter in Retirement Preparedness? Journal of Personal Finance, 14(2), 9-20.

Lee, J. M., \& Kim, K. T. (2016). The Role of Propensity to Plan on Retirement Savings and Asset Accumulation. Family and Consumer Sciences Research Journal, 45(1), 34-48.

Otoritas Jasa Keuangan. (2017). Strategi Nasional Literasi Keuangan Indonesia (Revisit 2017). Jakarta: Otoritas Jasa Keuangan.

Perry, V. G., \& Morris, M. D. (2005). Who is in Control? The Role of Self-Perception, Knowledge, and Income in Explaining Consumer Financial Behavior. Journal of Consumer Affairs, 39(2), 299-313.

Philip, P., Heaton, K., Atkinson, C., \& Brierley, N. (2018). Compare the Market's Financial Consciousness Index. Retrieved from https://www2.deloitte.com/content/dam/Deloitte/au/Documents/Economics/deloitte-aueconomics-financial-consciousness-index-060918.pdf

Sanusi, A. (2012). Metodologi Penelitian Bisnis. Jakarta: Salemba Empat.

Smith, H., Finke, M., \& Huston, S. (2012). The Influence of Financial Sophistication and Financial Planners on Roth IRA Ownership. Journal of Financial Service Professionals, (66(6)), 69-81.

Van Rooij, M. C. J., Lusardi, A., \& Alessie, R. J. M. (2011). Financial Literacy and Retirement Planning in the Netherlands. Journal of Economic Psychology, 32(4), 593-608. 